\title{
Diaphragmatic Herniation after Transthoracic Esophagectomy for Esophageal Cancer
}

\author{
Masaichi Ohira ${ }^{1}$, Naoshi Kubo ${ }^{1 *}$, Yoshito Yamashita ${ }^{2}$, Katsunobu Sakurai', Takahiro Toyokawa', Hiroaki Tanaka', Kazuya Muguruma ${ }^{1}$ and \\ Kosei Hirakawa ${ }^{1}$
}

${ }^{1}$ Department of Surgical Oncology, Osaka City University Graduate School of Medicine, Japan

${ }^{2}$ Department of Gastroenterological Surgery, Osaka City General Hospital, Japan

\begin{abstract}
Objectives: Diaphragmatic herniation $(\mathrm{DH})$ after transthoracic esophagectomy for esophageal cancer is a rare postoperative complication. This complication sometimes occurs suddenly and leads to a severe post-operative course. However, the incidence of and risk factors for $\mathrm{DH}$ are not fully documented.

Methods: In our institute, 340 patients with resectable esophageal cancer underwent right-sided transthoracic esophagectomy accompanied by laparoscopic or open gastric mobilization between April 2000 and January 2014. We retrospectively investigated the incidence of $\mathrm{DH}$ after surgery and risk factors for $\mathrm{DH}$.

Results: During this period, a total of 10 cases $(2.9 \%, 10 / 340)$ of $\mathrm{DH}$ occurred. In all cases, DH originated from the hiatus and extended to the left thorax. Time interval from initial surgery to surgery for DH widely varied (1 day57 months). Eight patients presented with sudden abdominal pain, while two patients had asymptomatic. DH was diagnosed using chest X-ray and/or CT scan in all cases. The hernial contents consisted of transverse colon in 4 cases, both transverse colon and small intestine in 4 cases. An incision of the left pleura around the esophageal hiatus and the direct route between left thorax and abdominal cavity were observed in all cases. Univariate analysis revealed that the laparoscopic approach of the abdominal cavity at the initial surgery were significant risk factors for $\mathrm{DH}$.

Conclusion: DH after transthoracic esophagectomy is relatively a rare but certain incidence of complication. Intraoperative prevention and careful postoperative attention might be required for $\mathrm{DH}$ after laparoscopic esophageal surgery.
\end{abstract}

Keywords: Diaphragmatic herniation; Esophagectomy; Esophageal cancer

\section{Introduction}

Esophageal carcinoma is the sixth leading cause of cancer death in the world [1]. The optimal treatment for resectable esophageal cancer is curative surgery, including transhiatal [2] or transthoracic [3] esophagectomy, accompanied by reconstruction of the digestive conduit. Cases of diaphragmatic herniation $(\mathrm{DH})$ after esophagectomy for esophageal cancer have been previously reported. $\mathrm{DH}$ is recognized as a low-risk postoperative complication causing abdominal contents in the large and small intestine to extend into the thoracic cavity via the esophageal hiatus. DH is reported to have a sudden onset and sometimes it leads to a severe postoperative course [4,5]. However, the risk factors and prevention methods have been not completely documented. Hence, we investigated and reported the incidence of DH and the associated risk factors in our institution. In addition, we suggest $\mathrm{DH}$ prevention methods after transthoracic esophagectomy.

\section{Material and Methods}

In this study, we retrospectively reviewed the medical records of 340 patients with esophageal cancer who underwent right-sided transthoracic esophagectomy accompanied by the reconstruction of gastric conduit at the Department of Surgical Oncology, Osaka City University Hospital, between April 2000 and December 2014.

The standard procedure for right-sided transthoracic esophagectomy accompanied by three-fields- lymphadenectomy in our institution has been previously reported [6-8]. In brief, during the thoracic phase of surgery, patients were placed in the left decubitus or prone position. Esophageal mobilization accompanied by lymphadenectomy of the periesophageal, post mediastinal, and supradiaphragmal lymph nodes in the middle and lower thorax and the lymph nodes around the left and right recurrent laryngeal nerves in the upper thorax were performed using either an open or thoracoscopic surgical approach. Afterwards, the patient was positioned in a supine position. Through a cervical collar incision, lymphadenectomy of the neck was performed by the cervical team. Simultaneously, the abdominal team mobilized the stomach by hand-assisted laparoscopic or open surgery. Reconstruction of the alimentary tract was performed by making a gastric conduit extracorporeally. A gastric conduit was pulled up through a post mediastinal or retrosternal route, and the cervical esophagogastric anastomosis was performed. When the retrosternal route of the gastric conduit was chosen, the esophageal hiatus was closed by suturing using a non-absorbable thread. In this period, 285 patients received the conduit reconstruction via post mediastinal route, while 55 patients underwent it via retrosternal route. After discharge from hospital, we followed up patients at the outpatient clinic. If they complained of any symptoms after discharge, we routinely performed X-ray and CT scans.

Clinicopathological data included histology, tumor location, and tumor-node-metastasis (TNM) stage. The pathological stage of cancer was based on the TNM classification system (version 7) of the American Joint Committee on Cancer (AJCC) and the Union of

*Corresponding author: Naoshi Kubo, Department of Surgical Oncology, Osaka City University Graduate School of Medicine, 1-4-3 Asahimachi, Abeno-ku, Osaka 545-8585, Japan, Tel: +81- 6-6645-3838; Fax: +81-6-6646-6450; E-mail: k-naoshi@ med.osaka-cu.ac.jp

Received May 04, 2015; Accepted June 12, 2015; Published June 19, 2015

Citation: Ohira M, Kubo N, Yamashita Y, Sakurai K, Toyokawa T, et al. (2015) Diaphragmatic Herniation after Transthoracic Esophagectomy for Esophageal Cancer. Surgery Curr Res 5: 233. doi:10.4172/2161-1076.1000233

Copyright: (C) 2015 Ohira M, et al. This is an open-access article distributed under the terms of the Creative Commons Attribution License, which permits unrestricted use, distribution, and reproduction in any medium, provided the original author and source are credited. 
International Cancer Control (UICC). In this study, we reported the patient background, symptoms, time interval from initial surgery, and type of initial surgery. In addition, we retrospectively investigated the incidence of DH after surgery and the risk factors for DH using univariate analysis. Informed consent was obtained from all patients in this study.

\section{Statistical Analysis}

Continuous data are presented as means and standard deviation. For data analysis, associations of categorical and numerical variables were assessed using the chi-square (and Fisher's exact test where applicable) and $t$-test, respectively. A $p$ value of $<0.05$ was considered statistically significant. SPSS software version 22 (SPSS, Inc., Chicago, IL, USA) was used for all analyses.

\section{Results}

There was a total of 10 cases (2.9\%: 10/340) of DH during this period. Patient demographics and clinic-pathological factors of $\mathrm{DH}$ after esophagectomy are shown in Table 1 . The male to female ratio was 8:2. The mean age was 63.0 years (ranged from 52 to 78 ). Eight cases had squamous cell carcinoma, while one case had carcinosarcoma and another one case had adenocarcinoma. All cases underwent a laparoscopic approach for initial surgery and underwent reconstruction of the gastric conduit via the post mediastinal route. DH was diagnosed by chest X-ray and Computed tomography in all cases.

All cases of $\mathrm{DH}$ originated from the hiatal and extended to the left thorax. We did not observe any cases in which the hernia contents extended to the right thorax. An incision of the left pleura around the esophageal hiatus and the direct route between left thorax and abdominal cavity were observed in all cases. The hernial contents comprised of the transverse colon in four cases, the small intestine in one case, both the transverse colon and small intestine in four cases, and both the right hemi-colon and small intestine in one case. The time interval from the initial surgery to the surgery for $\mathrm{DH}$ ranged from 1 day to 57 months. This interval was over one year for five cases and within one month for three cases. Regarding DH symptoms, eight cases experienced sudden abdominal pain, two cases experienced dyspnea, and two cases were asymptomatic. Six cases were surgically treated by reducing the hernia contents back into abdominal cavity and four cases underwent intestinal resection. All patients underwent surgical narrowing of the hiatus and the suturing of the gastric conduit and hiatus after reducing the hernia contents back into abdominal cavity. There were no mortality; however, one patient experienced recurrence of the hernia. Figure 1 shows chest X-ray and computed tomography images for patient 9 at the time of DH diagnosis. The transverse colon was extended to the left thorax via the esophageal hiatus. The patient underwent a resection of the incarcerated intestine and a temporary colostomy was performed. The postoperative course was uneventful. Table 2 shows the univariate analysis of the risk factors for $\mathrm{DH}$ in patients who underwent post-mediastinal route reconstruction using the gastric conduit. DH occurred more frequently in patients who underwent laparoscopic surgery of the abdomen compared with patients who underwent open surgery of the abdomen at the initial esophagectomy (5.9\% vs 0\%, $\mathrm{p}=0.007$ ). From April 2011, we performed the suturing of the gastric conduit and hiatus at the initial surgery to prevent the occurrence of DH (Figure 2). Despite this, DH still developed in two patients (case 9 and 10) after suturing between the gastric conduit and crus. From January 2014, during surgery we preserved the left pleura around the esophageal hiatus to prevent the occurrence of $\mathrm{DH}$. No patients who underwent transthoracic esophagectomy after January 2014 developed DH.

\section{Discussion}

DH after esophagectomy was initially reported in 1987 by Terz et al [9] . Since then, to the best of our knowledge, approximately 170 cases have been reported. In addition, several series studies regarding $\mathrm{DH}$ after esophagectomy have been reported [4,5,10-15]. Table 3 shows the incidence, clinical features, and the risk factors for $\mathrm{DH}$ reported in these studies. The incidence of DH was reportedly $0.69-19.4 \%$. DH predominantly occurred in the left chest and most of the hernia content was in the transverse colon. The time interval from initial surgery to

\begin{tabular}{|c|c|c|c|c|c|c|c|c|}
\hline SI. No & $\begin{array}{l}\text { Age } \\
\text { Gender }\end{array}$ & $\begin{array}{c}\text { Tumor } \\
\text { location } \\
\text { Stage }\end{array}$ & Initial surgery & Interval & Symptoms & $\begin{array}{l}\text { Surgical } \\
\text { treatment }\end{array}$ & Hernial content & $\begin{array}{c}\text { DH } \\
\text { recurrence }\end{array}$ \\
\hline 1 & $\begin{array}{c}68 \\
\text { male }\end{array}$ & $\begin{array}{c}\text { Middle } \\
2 a\end{array}$ & open-LA & 39 months & AP & BR colostomy & T-colon & absent \\
\hline 2 & $\begin{array}{c}56 \\
\text { male }\end{array}$ & $\begin{array}{c}\text { Upper } \\
4\end{array}$ & open-LA & 20 days & AP & $\mathrm{RHC}$ & SI & absent \\
\hline 3 & $\begin{array}{c}59 \\
\text { male }\end{array}$ & $\begin{array}{l}\text { Middle } \\
1 \mathrm{~b}\end{array}$ & open-LA & 57 months & AP & $\mathrm{RHC}$ & $\begin{array}{c}\text { T-colon } \\
\text { SI }\end{array}$ & absent \\
\hline 4 & $\begin{array}{c}54 \\
\text { male }\end{array}$ & $\begin{array}{l}\text { Middle } \\
1 \mathrm{~b}\end{array}$ & open-LA & 32 months & AP & $\mathrm{RHC}$ & $\begin{array}{c}\text { T-colon } \\
\text { SI }\end{array}$ & absent \\
\hline 5 & $\begin{array}{c}52 \\
\text { male }\end{array}$ & $\begin{array}{l}\text { Middle } \\
3 c\end{array}$ & open-LA & 3 months & AP & BR colostomy & T-colon & absent \\
\hline 6 & $\begin{array}{c}78 \\
\text { male }\end{array}$ & $\begin{array}{l}\text { Middle } \\
\text { 1a }\end{array}$ & TH-LA & 45 days & none & $\mathrm{RHC}$ & $\begin{array}{c}\text { T-colon } \\
\text { SI }\end{array}$ & present \\
\hline 7 & $\begin{array}{c}67 \\
\text { female }\end{array}$ & $\begin{array}{l}\text { Middle } \\
3 a\end{array}$ & TH-LA & 19 days & AP & $\mathrm{RHC}$ & T-colon & absent \\
\hline 8 & $\begin{array}{c}78 \\
\text { male }\end{array}$ & $\begin{array}{l}\text { Lower } \\
1 \mathrm{a}\end{array}$ & open-LA & 12 months & AP dyspnea & $\mathrm{BR}$ & $\begin{array}{l}\text { Rt- colon } \\
\text { SI }\end{array}$ & absent \\
\hline 9 & $\begin{array}{c}64 \\
\text { male }\end{array}$ & $\begin{array}{l}\text { Middle } \\
3 a\end{array}$ & open-LA & 16 months & AP dyspnea & $\mathrm{BR}$ & T-colon & absent \\
\hline 10 & $\begin{array}{c}54 \\
\text { female }\end{array}$ & $\begin{array}{l}\text { Lower } \\
2 a\end{array}$ & TH-LA & 1 day & none & $\mathrm{RHC}$ & T-colon & absent \\
\hline
\end{tabular}

LA: Laparoscopic gastric mobilization, TH: Thoracoscopic esophagectomy, AP: Abdominal pain, RHC: Reducing of hernia contents, BR: Bowel resection T-colon: Transverse colon, SI: Small intestine

Table 1: Clinical features of 10 patients with diaphragmatic herniation after transthoracic esophagectomy. 
Citation:Ohira M, Kubo N, Yamashita Y, Sakurai K, Toyokawa T, et al. (2015) Diaphragmatic Herniation after Transthoracic Esophagectomy for Esophageal Cancer. Surgery Curr Res 5: 233. doi:10.4172/2161-1076.1000233
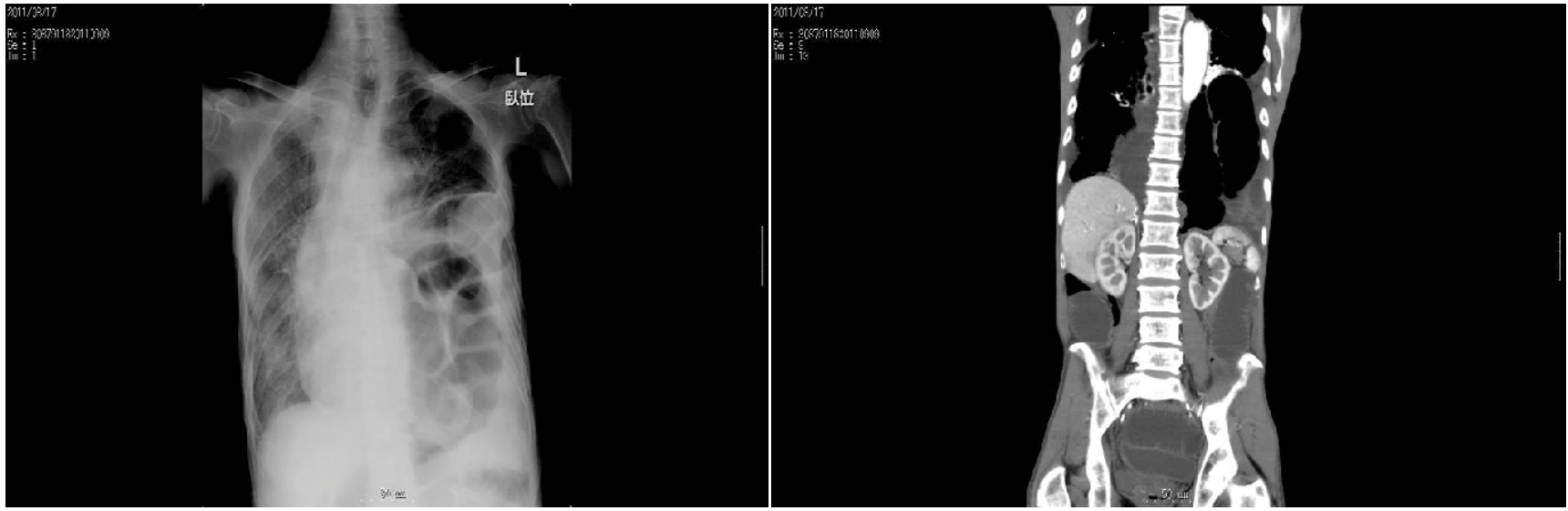

Figure 1: X-ray photo and computed tomography of the patient 9 with diaphragmatic hernia after esophagectomy. Transverse colon was extended to left chest via the esophageal hiatus (white arrow).

\begin{tabular}{|c|c|c|c|}
\hline \multicolumn{4}{|c|}{ Diaphragmatic hernia } \\
\hline & Present (10) & Absent (275) & $p$ value \\
\hline Age & $63.0 \pm 9.66$ & $63.6 \pm 8.31$ & 0.812 \\
\hline $\begin{array}{c}\text { Gender } \\
\text { (male/female) }\end{array}$ & $8 / 2$ & $222 / 53$ & 0.954 \\
\hline BMI & $20.5 \pm 3.30$ & $21.2 \pm 3.12$ & 0.445 \\
\hline \multicolumn{4}{|c|}{ Anastomotic site } \\
\hline cervical & 9 & 225 & \multirow{2}{*}{0.507} \\
\hline intrathoracic & 1 & 50 & \\
\hline \multicolumn{4}{|c|}{$\begin{array}{l}\text { Type of surgery } \\
\text { (abdominal part) }\end{array}$} \\
\hline laparoscopic & 10 & 157 & \multirow{2}{*}{0.007} \\
\hline open & 0 & 118 & \\
\hline
\end{tabular}

Table 2: The demographics and clinical features of patients with or without diaphragmatic herniation after esophagectomy followed by conduit reconstruction using stomach via postmediastinal route.

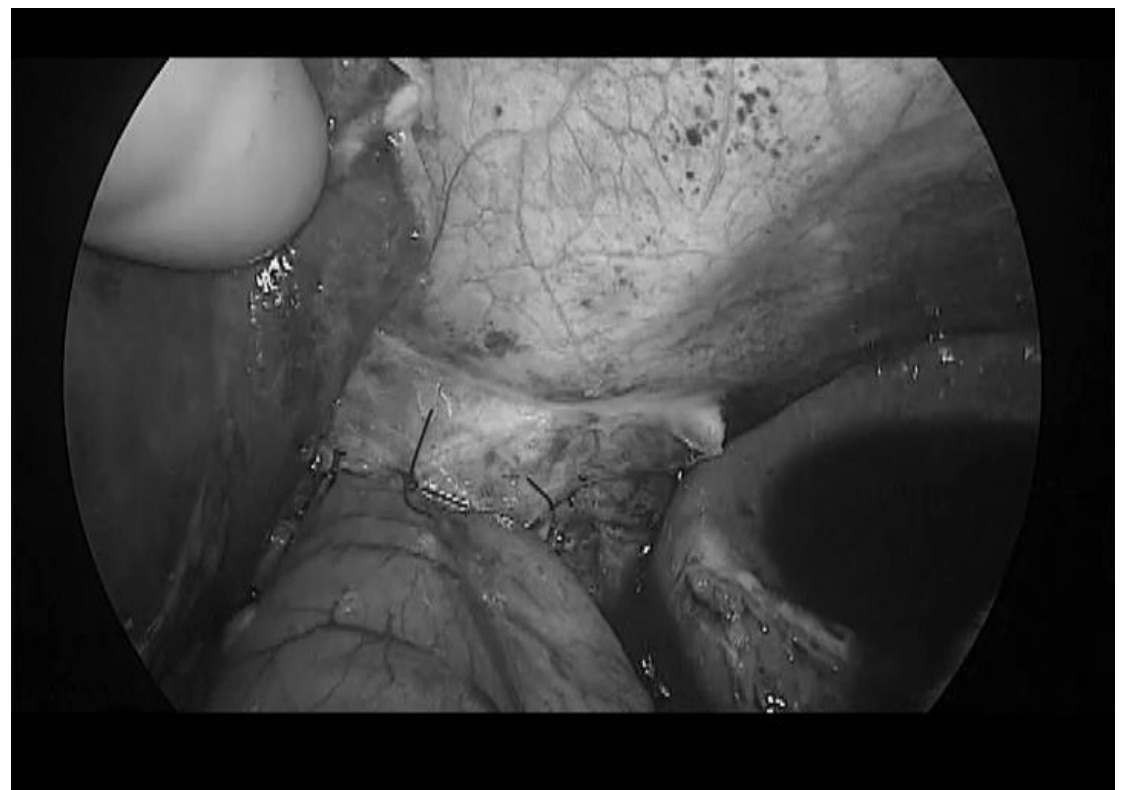

Figure 2: Laparoscopic view around esophageal hiatus after reconstruction by gastric conduit. Gastric conduit was tacked with the diaphragmatic crus. G: gastric conduit. 


\begin{tabular}{|c|c|c|c|c|c|}
\hline SI. No & Incidence (\%) & Type of initial surgery & Which thorax & Risk factors & Authors year \\
\hline 1 & $9 / 218(4.0)$ & THE in 5 TTE in 4 & NM & Incision of diaphragm & Van Sandic 1999 \\
\hline 2 & 9/355 (2.5) & TTE in 9 & left in 9 & NM & Vallbohmer 2007 \\
\hline 3 & $24 / 1075(2.2)$ & THE in 21 TTE in 3 & left in 21 right in 3 & MIS & Kent 2008 \\
\hline 4 & 7/36 (19.4) & THE in 7 & NM & Pre-existing hiatal hernia & Sutherland 2011 \\
\hline 5 & $15 / 2182(0.69)$ & TTE in 9 THE in 5 & left in 11 right in 2 bilateral in 1 & NM & Price 2011 \\
\hline 6 & $5 / 39(12.8)$ & TTE in 5 & NM & MIS & Willer 2012 \\
\hline 7 & $67 / 440(15.2)$ & THE in 25 TTE in 39 & $\begin{array}{l}\text { left in } 44 \text { right in } 3 \text { middle in } 19 \\
\text { bilateral in } 1\end{array}$ & BMI<25 Type of surgery (THE) & Ganeshan 2013 \\
\hline 8 & 9/114 (8.0) & THE in 2 TTE in 7 & NM & MIS & Bronson 2014 \\
\hline 9 & $10 / 340(2.9)$ & TTE in 10 & left in 10 & MIS & Our study 2015 \\
\hline
\end{tabular}

THE: Transhiatal Esophagectomy, TTE: Transthoracic Esophagectomy, NM: Not Mentioned, MIS: Minimally Invasive Surgery

Table 3: Series reports of diaphragmatic herniation after esophagectomy.

the occurrence of DH widely varied. The most commonly reported symptoms were nausea, vomiting, and abdominal pain related to bowel obstruction; shortness of breath and dyspnea related to a reduction of respiratory function were also reported. Regarding the type of initial surgery, some authors reported that transhiatal esophagectomy [14] and minimally invasive laparoscopic surgery $[10,13]$ were closely associated with $\mathrm{DH}$ compared with transthoracic esophagectomy and open abdominal surgery, respectively.

In this study, the incidence of $\mathrm{DH}$ was $2.9 \%$, which is consistent with previous reports. In addition, our study comprised patients who had initially undergone laparoscopic surgery. Previous reports $[10,13]$ demonstrated that a laparoscopic approach led to less adhesion of the abdominal contents, which contributes to an increased risk of $\mathrm{DH}$ compared with an open surgery approach. In this study, an incision of the left pleura around the esophageal hiatus and the direct route between left thorax and abdominal cavity were observed in all cases. We suggest that making an incision in the left pleura at the time of initial surgery may lead to $\mathrm{DH}$ of the left chest because $\mathrm{DH}$ was more likely to occur in the left chest than in the right chest. Previous reports have also showed that majority of DH cases extend to left thoracic cavity. The reason for left thoracic predominance of DH has been previously discussed. In summary, there may be two possible explanations for this predominance. One is an anatomical reason. The right-sided hiatal region is covered by the lateral segment and caudate lobe of the liver, which possibly prevents herniation into the right chest [5]. The second reason is related to the initial surgery. In general, greater curvature of the gastric conduit was seen on the left side of the hiatal region. Greater curvature of gastric conduit is less adhesive, whereas lesser curvature is more adhesive to the adjacent tissue because the cutting edge of the gastric conduit was at the right side of the hiatus, which adheres to adjacent right tissue $[10,15]$. Hence, $\mathrm{DH}$ is more likely to occur on the left chest through the left hiatal region. Making an incision in the left pleura around the esophageal hiatus may contribute to making a direct route from abdominal cavity to left thorax. Making an incision in the left pleura around the esophageal hiatus is performed not only for cases of lower esophageal mobilization during transhiatal esophagectomy and lower mediastinal lymphadenectomy during transthoracic esophagectomy. In those cases, preserving the left pleura around the esophageal hiatus may provide an important protection against the occurrence of $\mathrm{DH}$.

Another reports $[4,14]$ showed that widening the hiatus during initial esophagectomy was a risk factor for DH. In addition, Sutherland et al. [12] speculated that robotic mediastinal dissection caused the stretching of the hiatus when the surgery is high in the mediastinum and this increased the risk of DH. However, we found that the procedure for mobilizing the esophagus around the hiatus during initial surgery and the hiatal size after esophagectomy were equivalent in this study period.

Prevention of $\mathrm{DH}$ is of utmost importance. To prevent the occurrence of $\mathrm{DH}$, the following suggestions have been reported: (1) narrowing the hiatus by suturing the crus, [4] (2) Tacking between the crus and conduit $[4,10,11,14]$ (3) Repairing the hiatus using a mesh $[12,15]$ (4) performing colopexy (fixation of the transverse colon to the abdominal wall) [15]. In our experience, DH still developed in two patients after suturing between the gastric conduit and diaphragmatic crus at the initial surgery. Hence, we recently tried not only to preserve the left pleura around crus, but also to tack the conduit to the diaphragm. After introducing these procedures against the occurrence of $\mathrm{DH}$, we have experienced no cases of DH after esophagectomy.

This study had some limitations. This study involved only one institution, and it was a retrospective and not randomized study. In addition, there may have been small differences in the surgical procedure, which were not noted on the operative chart.

In conclusion, $\mathrm{DH}$ after transthoracic esophagectomy is a relatively rare but significant postoperative complication. Intraoperaive prevention and postoperative careful attention might be required for DH after laparoscopic esophageal surgery.

\section{Reference}

1. Jemal A, Bray F, Center MM, Ferlay J, Ward E, et al. (2011) Global cancer statistics. CA Cancer J Clin 61: 69-90.

2. Orringer MB, Marshall B, lannettoni MD (1999) Transhiatal esophagectomy: clinical experience and refinements. Ann Surg 230: 392-400.

3. Fujita H, Kakegawa T, Yamana H, Shima I, Toh Y et al. (1995) Mortality and morbidity rates, postoperative course, quality of life, and prognosis after extended radical lymphadenectomy for esophageal cancer. Comparison of three-field lymphadenectomy with two-field lymphadenectomy. Ann Surg 222: 654-662.

4. van Sandick JW, Knegjens JL, van Lanschot JJ, Obertop H (1999) Diaphragmatic herniation following oesophagectomy. Br J Surg 86: 109-112.

5. Vallbohmer D, Holscher AH, Herbold T, Gutschow C, Schroder W (2007) Diaphragmatic hernia after conventional or laparoscopic-assisted transthoracic esophagectomy. Ann Thorac Surg 84: 1847-1852.

6. Kubo N, Ohira M, Yamashita Y, Sakurai K, Toyokawa T, et al. (2014) The impact of combined thoracoscopic and laparoscopic surgery on pulmonary complications after radical esophagectomy in patients with resectable esophageal cancer. Anticancer Res 34: 2399-2340.

7. Kubo N, Ohira M, Yamashita Y, Sakurai K, Lee T, et al. (2014) Thoracoscopic esophagectomy in the prone position versus in the lateral position for patients with esophageal cancer: a comparison of short-term surgical results. Surg Laparosc Endosc Percutan Tech 24: 158-163. 
Citation:Ohira M, Kubo N, Yamashita Y, Sakurai K, Toyokawa T, et al. (2015) Diaphragmatic Herniation after Transthoracic Esophagectomy for Esophageal Cancer. Surgery Curr Res 5: 233. doi:10.4172/2161-1076.1000233

8. Hasegawa T, Kubo N, Ohira M, Sakurai K, Toyokawa T, et al. (2015) Impact of body mass index on surgical outcomes after esophagectomy for patients with esophageal squamous cell carcinoma. J Gastrointest Surg 19: 226-233.

9. Terz JJ, Beatty JD, Kokal WA, Wagman LD (1987) Transhiatal esophagectomy. Am J Surg 154: 42-48.

10. Kent MS, Luketich JD, Tsai W, Churilla P, Federle M, at al. (2008) Revisiona surgery after esophagectomy: an analysis of 43 patients. Ann Thorac Surg 86: 975-83.

11. Price TN, Allen MS, Nichols FC, Cassivi SD, Wigle DA, et al. (2011) Hiatal hernia after esophagectomy: analysis of 2,182 esophagectomies from a single institution. Ann Thorac Surg 92: 2041-2045.
2. Sutherland J, Banerji N, Morphew J, Johnson E, Dunn D (2011) Postoperative incidence of incarcerated hiatal hernia and its prevention after robotic transhiatal esophagectomy. Surg Endosc 25: 1526-1530.

13. Willer BL, Worrell SG, Fitzgibbons RJ Jr., Mittal SK (2012) Incidence of diaphragmatic hernias following minimally invasive versus open transthoracic Ivor Lewis McKeown esophagectomy. Hernia 16: 185-190.

14. Ganeshan DM, Correa AM, Bhosale P, Vaporciyan AA, Rice D, et al. (2013) Diaphragmatic hernia after esophagectomy in 440 patients with long-term follow-up. Ann Thorac Surg 96: 1138-1145.

15. Bronson NW, Luna RA, Hunter JG, Dolan JP (2014) The incidence of hiatal hernia after minimally invasive esophagectomy. J Gastrointest Surg 18: 889-893. 